\title{
Rectus sheath hematoma, rare condition, difficult diagnosis and multidisciplinary treatment: report of 5 cases
}

\author{
Antonio Martino ${ }^{1}$, Ciro De Martino ${ }^{2 *}$, Anna Pisapia², Gautam Maharajan1, Marco Evangelista ${ }^{1}$ \\ From XXIII Annual Meeting of the Italian Society of Geriatric Surgery \\ Lecce, Italy. 2-4 December 2010
}

\section{Background}

Rectus sheath hematoma is a rare condition. It encompasses a wide spectrum of severity (self-limiting to fatal) depending on its size, etiology, and the development of complications. It has multiple possible etiologies including, frequently, coagulation disorders or anticoagulation therapy. It enters into the differential diagnosis of abdominal pain but it's frequently difficult to diagnose and radiological imaging is often required.

\section{Methods}

We report a series of five patients that came to our hospital within a 8 -month period. The patients were between 63 to 78 years old. One of them was in therapy with warfarin, one was in therapy with acetilsaliciliate and clopidogrel and in an another patient, a coagulation disorder was detected. Diagnosis was suspected in all cases by clinical exam and ultrasonography, but CTscan was necessary in three cases. All patients underwent conservative treatment, mainly pain relief and rest. In two cases blood transfusion was performed and in two cases clotting abnormalities were corrected with vitamin $\mathrm{K}$ and fresh frozen plasma. After being discharged, patients were followed up on as outpatients.

\section{Results}

All patients were treated conservatively. Average hospitalization was 10 days (range 5-17 days). The patient healed within three months at least. One patient developed infection of the hematoma and was treated with ultrasound-guided aspiration and antibiotics.

\section{Conclusions}

Rectus sheath hematoma is a rare but important entity in the differential diagnosis of abdominal pain. Interdisciplinary awareness of this condition is essential, as it is frequently difficult to diagnose, leading to delay in treatment or unneeded surgery. CT-scan is the gold-standard investigation. Treatment options are variable and include conservative treatment, intravascular embolization and surgery. Frequently an interdisciplinary team approach is needed.

\section{Author details}

${ }^{1}$ Casa di Cura "A. Grimaldi" di San Giorgio a Cremano (NA). Dipartimento di Chirurgia, Italy. ${ }^{2}$ Università degli Studi di Napoli "Federico II". U.O.C. di Chirurgia Generale, Naples, Italy.

Published: 24 August 2011

\section{References}

1. Luhmann S, Williams EV: Rectus sheath hematoma: a series of unfortunate events. World J Surg 2006, 30:2050-55.

2. Alla VM, Karnam SM, Kaushik M, Porter J: Spontaneous rectus sheath hematoma. West J Emerg Med 2010, 11(1):76-9.

3. Ergun N, Cevic AA, Holliman CJ: Conservative management of giant abdominal wall hematoma. Ulus Trauma Derg 2004, 10:141-144.

doi:10.1186/1471-2318-11-S1-A29

Cite this article as: Martino et al:: Rectus sheath hematoma, rare condition, difficult diagnosis and multidisciplinary treatment: report of 5 cases. BMC Geriatrics 2011 11(Suppl 1):A29.

\footnotetext{
* Correspondence: ciro.de@tiscali.it

¿Università degli Studi di Napoli "Federico II". U.O.C. di Chirurgia Generale, Naples, Italy

Full list of author information is available at the end of the article
} 